\title{
Desenvolvimento de Macarrão Instantâneo com Farinha de Maçã e Adição de Cafeína e Taurina
}

\author{
Natália F. de Medeiros, Vitor C. Meleiro \& Samer Pereira
}

O objetivo deste trabalho foi desenvolver um macarrão instantâneo energético com substituição parcial da farinha de trigo (FT) por farinha de maçã (FM), proporcionando valor nutricional maior e consequentemente efeitos fisiológicos e metabólicos benéficos, devido à adição de cafeína e taurina no molho complementar. O produto desenvolvido apresentou alto teor proteico, conformidade com os parâmetros de qualidade microbiológica, exigidos pela legislação e alta aceitabilidade (93\%) na avaliação sensorial. A substituição da FM por FT contribuiu qualitativas e quantitativas com relação à sua composição centesimal e o produto desenvolvido demonstrou viabilidade de produção.

Palavras- Chave: Macarrão instantâneo; farinha de maçã; energético.

The aim of this study was to develop an energetic instant noodles with partial substitution of wheat flour (FT) for apple flour (FM), providing greater nutritional value and hence physiological and metabolic effects beneficial due to the addition of caffeine and taurine in complementary sauce. The developed product showed high protein content, compliance with microbiological quality parameters required by the legislation and high acceptability (93\%) in the sensory evaluation. The replacement of FM FT contributed qualitative and quantitative with respect to its chemical composition and the developed product showed production feasibility.

WordsKey: Instant noodles; apple flour; energy. 


\section{Introdução}

A RDC n 263, de 22 de setembro de 2005 da ANVISA $^{3}$, atualmente em vigor no Brasil, define macarrão instantâneo ou massa alimentícia instantânea como o produto não fermentado, apresentado de diversas formas, recheado ou não, obtido pelo empasto, amassamento mecânico, cozimento e desidratação ou não da mistura de farinha de trigo ou sêmola/semolina de trigo durum e ou farinha de outros vegetais, adicionado ou não de outros ingredientes, acompanhado ou não de temperos e ou complementos, isoladamente ou adicionados diretamente à massa. Para seu preparo, o o produto é reidratado a frio ou a quente e o tempo de cozimento é reduzido ou desnecessário.

Esse alimento está inserido no grupo dos carboidratos complexos, apresentando um índice glicêmico entre baixo e moderado, sendo sua ingestão recomendada na alimentação escolar e hospitalar. Entretanto, em termos de valor nutricional, este alimento é deficiente, uma vez que se destaca pela sua riqueza em carboidratos (75\%) em detrimento a quantidade e qualidade de proteínas ( $12,35 \%$ de proteína, sendo $0,74 \mathrm{mg} \%$ de lisina e 0,35 $\mathrm{mg} \%$ de metionina) ${ }^{10}$.

O desenvolvimento de um macarrão instantâneo com substituição parcial da farinha de trigo por farinha de maçã e adição de cafeína e taurina torna este produto diferenciado com características funcionais e energéticas. A farinha de maçã contribui para o consumo de fibras solúveis na dieta alimentar podendo desempenhar um papel importante na prevenção de doenças cardiovasculares com a perda de peso e no tratamento da obesidade por aumentar a sensação de saciedade pósalimentar reduzindo o apetite ${ }^{12}$.

A taurina sendo o aminoácido condicionalmente essencial para os seres humanos com ingestão diária de fibras solúveis evidencia as possíveis aplicações clínicas e o seu envolvimento na prevenção da degeneração da retina, sendo considerado também um aminoácido semiessencial em situações de estresse ou desnutrição 11, 13, 14. A cafeína, um derivado trimetilado da xantina, ao ser ingerida oralmente é absorvida rapidamente pelo trato gastrointestinal, podendo provocar importantes alterações fisiológicas no desempenho atlético, e em conjunto com taurina proporciona um efeito de equilíbrio cárdico, aumentando a disposição do individuo ${ }^{4}$.
Nesse contexto, o objetivo do presente trabalho foi o desenvolvimento de um macarrão instantâneo, contendo em sua formulação ingredientes com propriedades funcionais distintas, melhorando sua composição nutricional e que atenda aos parâmetros físico-químicos, sensoriais e microbiológicos legais vigentes, bem como as exigências do mercado consumidor quanto à qualidade tecnológica de um produto inovador.

\section{Materias e Métodos}

\section{PROCESSO DE OBTENÇÃO DO MACARRÃO INSTANTÂNEO}

Para a realização deste trabalho, as maçãs da variedade Pomerana foram adquiridas no comércio local da cidade de Vassouras-RJ. A elaboração da farinha ocorreu nas dependências do CTS SENAI Alimentos e Bebidas, localizado no município de Vassouras-RJ. Para o desenvolvimento do macarrão instantâneo utilizou-se a farinha de maçã e procedeu-se a elaboração da seguinte formulação: farinha de trigo $(62,5 \%)$, farinha de maçã (9,6\%), sal $(0,73 \%)$, ovo $(23,14 \%)$, água $(4,03 \%)$, cafeína e taurina $(\mathrm{mg} / \mathrm{sachê})$.

O produto foi elaborado através das etapas mostradas pelo fluxograma da figura 1. Na etapa extrusão e porcionamento a massa alimentícia recebe a forma característica de macarrão especificamente de seu tipo. Foram distribuídas porções iguais de macarrão de forma manual, utilizando balança para a pesagem de unidades contendo em média $151 \mathrm{~g}$, para obtermos $68 \mathrm{~g}$ de massa devido ao seu rendimento de $45 \%$ da massa cozida para a massa instantaneizada. Já na etapa de instantaneização a massa seca foi imersa em óleo (quente/fervente) com temperatura correspondente á, em média, $80^{\circ} \mathrm{C}$ por 10 a 20 segundos, para a produção do macarrão instantâneo obtido por um processo de secagem/desidratação por fritura (umidade). A secagem é feita após a saída do macarrão do processo de fritura, em que esse absorveu altos índices de lipídeos que serão parcialmente eliminados, durante esta etapa, em forno industrial a uma temperatura correspondente a $150^{\circ} \mathrm{C}$ durante 2 minutos. No empacotamento, o macarrão foi cortado e empacotado manualmente em polipropileno (PP) tipo $5 \mathrm{em}$ pacotes de $68 \mathrm{~g}$, seguindo as especificações do produto. 


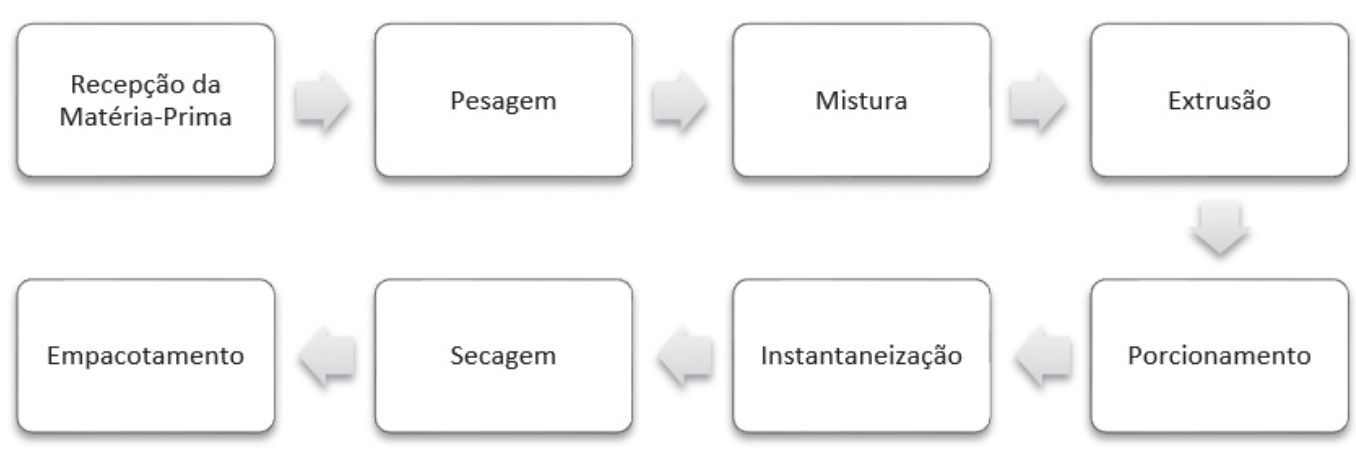

Figura 1: Fluxograma de Processamento de Macarrão Instantâneo.

\section{ANÁLISES FÍSICOS QUÍMICAS E MICROBIOLÓGICAS}

O macarrão instantâneo foi submetido às análises de composição centesimal, realizadas em triplicatas, conforme metodologias do Instituto Adolfo Lutz ${ }^{6}$.

As análises microbiológicas foram realizadas, conforme a RDC 12/2001, em que foram pesquisados Coliformes a $45^{\circ} \mathrm{C}$ de no máximo $10^{2} \mathrm{NMP} / \mathrm{g}$, Staphylococcus coagulase positivo no máximo $5 \times 10^{3} \mathrm{UFC/g}$, Salmonella spp. ausência em $25 \mathrm{~g}$ e para Bacillus Cereus, máximo de $3 \times 10^{3} \mathrm{UFC} / \mathrm{g}$, seguindo a metodologia padrão preconizada pela $\mathrm{APHA}^{1}$.

\section{ANÁLISE SENSORIAL}

As análises sensoriais foram realizadas na sala de degustação no CTS Alimentos e Bebidas, com 50 participantes, maiores de 15 anos, sendo estes funcionários e alunos, entre homens e mulheres.

Foi realizado o teste de aceitação por escala hedônica de 3 pontos, sendo as alternativas descritas como gostei, indiferente e desgostei, foram coletadas as informações de frequência de consumo e atividade física, para fins estatísticos ${ }^{9}$.

\section{Resultados e Discussões}

\section{ANÁLISES FÍSICO-QUÍMICAS}

A composição centesimal para o macarrão instantâneo com substituição parcial de farinha de maçã (MISFM) e para massas instantâneas, conforme os padrões legislativos da RDC n93 (2000) e da Tabela Brasileira de Composição de Alimentos - TACO (2011) encontra-se na Tabela 1.
Tabela 1. Resultados das determinações analíticas do MISFM.

\begin{tabular}{|c|c|c|c|}
\hline Análises (\%) & MISFM (\%) & Legislação (\%) & TACO (\%) \\
\hline Umidade & $8,58 \pm 0,94$ & 10,0 (Máx.) & 6,0 \\
\hline Cinzas & $3,43 \pm 2,72$ & 2,5 (Máx.) & 5,6 \\
\hline Proteínas* & $12,06 \pm 0,00$ & $8-15$ & 8,8 \\
\hline Lipídios & $15,86 \pm 0,41$ & NA & 17,2 \\
\hline Carboidratos & $6,37 \pm 0,04$ & NA & 62,4 \\
\hline $\begin{array}{c}\text { Ac. Titulável } \\
\text { (mg/100g) }\end{array}$ & $9,91 \pm 0,01$ & 3,0 (Máx.) & NA \\
\hline Pectinas & $1,2 \pm 0,05$ & NA & NA \\
\hline $\begin{array}{c}\text { Índice de } \\
\text { Peróxido }\end{array}$ & 0 & 30,0 (Máx.) & NA \\
\hline
\end{tabular}

Os resultados encontrados para as análises de umidade, proteínas e índice de peróxido estão de acordo com os limites estabelecidos pela legislação vigente. Já para as análises de lipídeos, carboidratos e pectinas não há limites estabelecidos.

O MISFM apresentou valores de acidez entre $9,91 \pm 0,01 \%$, tais valores encontram-se superior ao padrão citado pela Agência Nacional de Vigilância Sanitária ${ }^{2}$, que recomenda para massas instantâneas um teor máximo de 3,0 em ml de solução $\mathrm{N}$ de $\mathrm{NaOH} / 100 \mathrm{~g}$ de acidez, pois uma variação além desse limite, deve ser considerada como um sinal de alarme sob o ponto de vista sanitário.

A acidez de um alimento pode ser originada dos próprios compostos naturais do alimento, pode ser formada pela fermentação ou pelo tipo de processamento pelo qual o alimento passou e, ainda, ser o resultado da deterioração que esse sofreu ${ }^{5}$, por isso, acidez elevada pode ser um indicativo de perda de qualidade do produto. 
Em relação ao teor médio de cinzas, foram encontrados 3,43 $\pm 2,72 \%$ no MISFM, valor superior ao dos parâmetros legislativos da $\mathrm{RDC} \mathrm{n}^{\circ} 93$ (2000) de massas instantâneas para cinzas, que estabelece máximo de 2, 5\% e inferior ao determinado pela Tabela (TACO) que foi de 5,6. Esse fato resulta do aporte de minerais, como cálcio, magnésio e potássio, consideravelmente presentes na maçã ${ }^{13}$.

\section{QUALIDADE MICROBIOLÓGICA}

Os resultados das análises microbiológicas, apresentados na tabela 2, evidenciaram que o produto presentou características microbiológicas adequadas, uma vez que os valores obtidos estão abaixo dos padrões exigidos na vigente, indicando que a matéria-prima e o macarrão foram processados em condições adequadas.

Tabela 2: Caracterização microbiológica do Macarrão Instantâneo.

\begin{tabular}{|c|c|c|}
\hline Análises & MISFM & $\begin{array}{c}\text { Legislação Massas } \\
\text { Alimentícias }\end{array}$ \\
\hline $\begin{array}{c}\text { Baccilus Cereus } \\
(* \text { UFC/g) }\end{array}$ & $<10 \mathrm{UFC} / \mathrm{g}$ & $\begin{array}{c}3 \times 10^{3} \mathrm{UFC} / \mathrm{g} \\
\text { (Máx.) }\end{array}$ \\
\hline $\begin{array}{c}\text { Coliformes a } 45^{\circ} \mathrm{C} \\
(* * \mathrm{NMP} / \mathrm{g})\end{array}$ & $3,6 \mathrm{NMP} / \mathrm{g}$ & $10^{2} \mathrm{NMP} / \mathrm{g}$ (Máx.) \\
\hline $\begin{array}{c}\text { Salmonella sp. } \\
(* * * \text { UFC/25g) }\end{array}$ & Ausência/ $25 \mathrm{~g}$ & Ausência/25g \\
\hline $\begin{array}{c}\text { Staphylococcus } \\
\text { Coagulase Positivo } \\
(* \text { UFC/g) }\end{array}$ & $<10 \mathrm{UFC} / \mathrm{g}$ & $\begin{array}{c}5 \times 10^{3} \mathrm{UFC} / \mathrm{g} \\
\text { (Máx.) }\end{array}$ \\
\hline
\end{tabular}

\section{ANÁLISE SENSORIAL}

$\mathrm{Na}$ Figura 2, estão apresentadas as avaliações sensoriais de aceitabilidade, em escala hedônica de 3 pontos, de gostei, indiferente e desgostei.

É perceptível que 93\% dos julgadores optaram por gostei, enquanto uma pequena parcela escolheu a opção indiferente $(6 \%)$ e desgostei (1\%), indicando com isto, que o macarrão obteve uma excelente aceitabilidade por eles. Os resultados encontrados nesse estudo foram baixos, quando comparados com os valores de MALUF 8, que obteve uma aceitabilidade de $97 \%$ na elaboração de massa fresca de macarrão enriquecida com pescado defumado e 97, 30\% de aceitabilidade encontrado por NICOLETTI 10 no enriquecimento nutricional de macarrão com uso subprodutos agroindustriais de baixo custo.

\section{GÊNERO DOS PROVADORES}

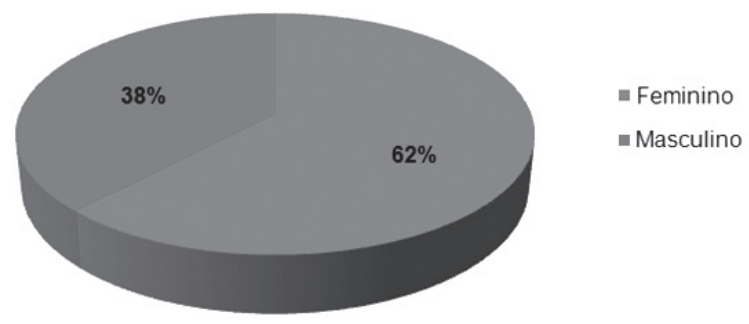

Figura 2: Aceitação por escala hedônica de 3 pontos.

\section{Conclusão}

A partir dos resultados obtidos neste trabalho, foi possível a elaboração do macarrão instantâneo com substituição parcial da farinha de trigo pela farinha de maçã. Pode-se verificar que o macarrão instantâneo preparado com a farinha de maçã apresentou valor proteico $(12,06 \%)$ superior ao limite da legislação (mínimo de $8-15 \%$ ) e da Tabela TACO (8,8\%). As análises microbiológicas encontram-se dentro dos padrões microbiológicos, tornando o produto satisfatório para o consumo humano. $\mathrm{Na}$ avaliação sensorial, o produto apresentou ótima aceitabilidade com 93\% de aprovação. Assim é viável a inclusão desse alimento como alimento processado e como produto inovador.

\section{Referências}

1. Apha/Awwa/Wef. Eaton, A.D (2005).; et al. Standard methods for the examination of water and food. $21^{\mathrm{a}}$ ed. Washington: American Public Health Association. $1082 \mathrm{p}$

2. Brasil. Ministério da Saúde. Agência Nacional de Vigilância Sanitária. Resolução - RDC n93, de 31 de outubro de 2000. Regulamento técnico para fixação de identidade e qualidade de massas alimentícia. Diário Oficial da União; Poder Executivo, 01 nov. 2000.

3. Brasil. Ministério da Saúde. Agência Nacional de Vigilância Sanitária. Resolução - RDC nº 263, de 22 de setembro de 2005. Aprova o Regulamento Técnico para produtos de cereais, amidos, farinhas e farelos. Diário Oficial da República Federativa do Brasil, Brasília, DF, 23 set. 2005.

4. Carvalho, J. M. et al. Perfil dos principais componentes em bebidas energéticas: cafeína, taurina, guaraná e glucoronolactona. Rev Inst Adolfo Lutz, v. 65, n. 2, p. 78-85, 2006. 
5. Fernandes, A. F. et al. Efeito da substituição parcial da farinha de trigo por farinha de casca de batata (Solanum Tuberosum Lineu). Ciênc. Tecnol. Aliment., vol.28, suppl. 0, pp. 56-65, Dez. 2008 . Disponível em: . Acesso em: 10/10/2015.

6. Instituto Adolfo Lutz - Normas Analíticas; métodos químicos e físicos para a análise de alimentos. 4 ed. São Paulo: Instituto Adolfo Lutz, 2008.

7. Jones, P. J. Clinical nutrition: 7. Functional foods - more than just nutrition. Clinical Basics, Montreal, v. 166, n. 12, p. 1555-1563, 2002.

8. Maluf, Márcia Luzia Ferrarezi. Elaboração de massa fresca de macarrão enriquecida com pescado defumado. Rev. Inst Adolfo Lutz. 2010; 69(1):84-90.

9. Minim, V. P. R. Análise Sensorial: estudo com consumidores. Viçosa, MG: Ed. UFV, 2006. 225 p.

10. Nicoletti, A. M. Enriquecimento nutricional de macarrão com uso de subprodutos agroindustriais de baixo custo. 2007. 80f. Dissertação (Mestrado em Ciência e Tecnologia de Alimentos) Universidade Federal de Santa Maria, Santa Maria, 2007.

11. Redmond H. P, Stapleton Pp, Neary P, Bouchier-Hayes D. Immunonutrition: the role of taurine. Nutrition. 1998;14:599-604. Review.

12. Schaffer S, Solodushko V, Azuma J. Taurine-deficient cardiomyopathy: role of

13. Scheeren, P. et al. Aproveitamento de maçãs não conformes à comercialização na elaboração de pães. Revista destaques acadêmicos - CETEC/UNIVATES, v. 4, n. 4, p. 67-75, 2012.

14. Schuller-Levis G.B., Gordon R.E., Wang C., Park E.: Taurine reduces lung inflammation and fi brosis caused by bleomycin. Adv. Exp. Med. Biol., 2003; 526: 395-402.

\section{Natália F. de Medeiros* ; Vitor C. Meleiro \& Samer Pereira}

Rua: Prefeito Antônio Caramez, 1007, Bairro: Santa Rita, Cidade: Mendes/RJ, C.E.P.: 26700-000.

*E-mail.vmeleiro@gmail.com 